American Journal of Art and Design
2020; 5(3): $59-62$
http://www.sciencepublishinggroup.com/j/ajad
doi: 10.11648 /j.ajad.20200503.11
ISSN: $2578-7799$ (Print); ISSN: $2578-7802$ (Online)

\title{
Research on the Dilemma of Sustainable Fashion Design
}

\author{
Yizhou Zhang \\ School of Culture Communication \& Design, Zhejiang University of Finance \& Economics Dongfang College, Hangzhou, China \\ Email address: \\ 188496172@qq.com \\ To cite this article: \\ Yizhou Zhang. Research on the Dilemma of Sustainable Fashion Design. American Journal of Art and Design. Vol. 5, No. 3, 2020 , pp. 59-62. \\ doi: 10.11648/j.ajad.20200503.11
}

Received: June 11, 2020; Accepted: July 28, 2020; Published: August 5, 2020

\begin{abstract}
With a constant production increase, fibre is made into over 150 billion garments in a long and dispersive supply chain; as a result of the mutual stimulation of demand and output, garment production has repeatedly surged to new highs; while bringing economic benefits, the rapid growth of fashion industry has also had a profound negative impact on social culture and natural environment, and fashion industry has become one of the most polluted industries in the world after petroleum and gas; Fiber continues to increase production and is manufactured into more than 150 billion pieces of clothing in a long and scattered supply chain. The mutual stimulation of demand and output has made clothing output record high, high growth brings economic benefits and also allows the fashion industry social humanities and the natural environment had a profound negative impact on fashion but also became one of the world's oil and gas after the worst industrial pollution, consumerism-driven fashion culture among contemporary construction of ecological civilization and there is a fierce internal Contradiction, clothing as the main material embodiment of fashion culture, the sustainable correction of its design is the basic means to solve this contradiction. However, there are many difficulties in the process of sustainable correction of clothing design, such as ethical divergence, loss of design value, lack of design theory and methodology system, lack of educational resources, and constraints of the actual environment. It is a prerequisite for designers to develop sustainable fashion design practices and develop sustainable fashion culture to discover and confront these acute problems.
\end{abstract}

Keywords: Fashion Design, Sustainable, Dilemma

\section{Introduction}

With the increasingly abundant material life, people's pursuit of fashion has been expanding, and while bringing great economic benefits to the industry, the unrestrained fashion consumption also poses great threats to culture and environment. [1] It has become a major research topic for fashion designers in recent years to solve this contradiction by setting up new values, establishing a complete sustainable design system and promoting the education of sustainable fashion design. However, the sustainable correction of fashion design depends more than just the innovation of a certain technical method or the establishment of a certain regulation and policy, although considerable achievements have been made in existing research, the road ahead remains long and difficult [2].

\section{The Ethical Deviation Between Fashion Culture and Ecological Civilization Driven by Consuming Desires}

Clothing is a basic way for humans to show themselves to the society, which intensively "reflects the basic need for prominence and integration in human nature" [3]. Therefore, the current fashion consumption represented by clothing is often driven by psychological needs, and clothing has become a tool for consumers to acquire self-identity and social identity, forcing them to purchase again and again. Fashion has been dubbed "the market-driven consumption desire and demand cycle" and "the modern mechanism of self-manufacture", this kind of unrestrained circular consumption runs counter to the ecological ethics advocated nowadays and is thus criticized by the society as a "meaningless, worthless, useless and transient industry". This kind of "immoral" fashion culture has raised the alarm of the whole society. [4] In this context, the first is to 
clarify the principles and norms of sustainable fashion ethics. A sustainable fashion culture should be based on "goodwill", Mr. Hang Jian even pointed out that it should be "an angle, an attitude and a stance"; secondly, the "degree" of sustainable fashion ethics should be explored, for if the ethical requirements are too low, they do not have the ability of restraining and guiding, while if they are too high, they may cause practitioners to lose their practical ability in order to follow perfect moral requirements. However, although some stakeholders of the fashion industry are aware of the risks and crises, they are still intentionally or unintentionally downplaying the discussion of fashion ethics. Therefore, there is an urgent need for the serious discussion of the ethical issues of today's sustainable fashion guided by the government, led by activists and participated by practitioners and consumers [5].

\section{The Value Loss of Fashion Design in the Context of a Consumerist Fashion Culture}

The influence of the fashion industry represented by clothing on social culture and ecological environment is often considered as material. As a result, designers tend to regard design methods and technical means as the primary research direction and content when conducting sustainable correction of fashion design. In A New Explanation of the Dialogues in Protagoras, Derek Anderson pointed out that the ecological crisis he is concerned with is not a technical failure but a philosophical one, which the author finds quite insightful. In order to realize really sustainable fashion design, designers should first have a general consensus on the value of "sustainability". [6] However, in reality, designers generally recognize the general meaning of sustainability, that is, to find a balance between short-term economic interests and long-term ecological interests, yet due to the differences between individuals in such aspects as social environment, economic condition and education background, once specific interests are concerned, designers may hold totally different opinions on this term. For example, in regions with relatively developed economy and favorable fashion environment, fashion stakeholders often have the ability and the responsibility to sacrifice more short-term economic interests, and the designers and enterprises there are also willing to pay a higher price for long-term ecological values, reflecting a higher value identity and requirements for sustainability. However, there is also the problem of idealizing sustainable values and imposing values inappropriate in the local conditions, indicating a possibility of value "kidnapping" and "bullying". While expressing her sustainable values and having positive influence on the world's environmental protection, the impassioned statements of the 16-year-old "environmental girl" from Sweden has made those in developing areas feel that she's asking "why don't you eat meat paste now that you don't have rice?" Value is the cornerstone of the design and production of products, which is not only closely linked to sustainable design. Balancing the short-term interests and long-term interests with the current environmental limitations, thus truly realizing environmental protection, affluence, development, fairness and human welfare, is of a far-reaching significance. In order to achieve this goal, it's necessary to fundamentally rethink the values of fashion stakeholders especially fashion designers, and thinking from the perspective of sustainable values and sustainable design is the foundation of the development of sustainable fashion culture. [7]

\section{The Absence of a Unified and Efficient System of Theories and Methodologies of Sustainable Fashion Design}

The current mainstream theoretical system of fashion design has a profound historical origin, a clear ideological system, a complete knowledge pedigree, clear connotation boundaries and mature methodologies to guide practice, forming a complete system of theories and methodologies on which the work of most fashion designers is based. However, although the sustainable correction of fashion design seems to be just the addition of an adjective on the original concept, the adjective is by no means a simple modification but a real reform. [8] As an extension of the trend of green design, the research scope of sustainable design has been extended from simply the sustainability of natural resources to a wider social scope, with a pursuit of the "justice" of design. Many schools of sustainable design have emerged, and some scholars from Permaculture and Biominicy have taken a bionic perspective, arguing that product design should imitate nature so as to achieve a balance between man and the nature. However, since these these studies were mostly based on agro-ecological theories, they are inevitably incompatible with the actual practice in the current industrial society. Some other scholars of "emotional durable design", on the other hand, held that clothing consumption should be more spirit-driven rather than material-driven, so the emphasis should be laid on building emotional connections between clothing and consumers, thus truly prolong the life of clothing and reducing unnecessary clothing consumption. However, the ways, the processes and the results of emotion connection building are extremely personalized among individual consumers, and the interaction experience between consumers and clothing products is random and hard to predict, which has made it difficult to control the process and result of this approach of design. In addition, relevant data have shown that there's no clear negative correlation between the service life of clothing products and clothing consumption, which means that simply increasing the service life of clothing products can not help achieve the goal of slowing down the re-consumption of clothing. Besides, other scholars advocate the sustainable design concept of "service replace product", hoping to guide the transformation of the consumers from owning clothing products to serving for the owning through design. Theoretically speaking, not only can this concept of design 
meet the fashion consumers' demand for clothing, but it can also reduce the idle and discarding rate of clothing, thus giving full play to the value of clothing. This model of shared clothing has been widely applied, and such platforms as YCLOSET, MSPARIS and Wuxian Zuyi have been well recognized by the market, yet such problems as poor user experience, uneven clothing quality and tedious rental rules have kept emerging. Is this but a capital game in a booming sharing economy or the real way for the future of sustainable fashion? Let wait and see. William Mcdonough, an American scholar and Michael Braungart, a German chemist held that the previously mentioned methods of design aiming at simply reducing consumption could not truly achieve sustainability. In their book From Cradle to Cradle: Remaking the Way We Make Things, they proposed an approach of design totally different from the previous path "from cradle to grave" [9]. They pointed out that a new revolution of industrial production was needed, in which all the materials elements of the production process could be regenerated into production means or technical means, thus realizing the true abundance of mankind. Very good achievements in sustainability have been made through this approach in developed countries. For example, the SOEX Group of Germany has advanced recycling technologies, a complete classification system of discarded clothing, a convenient collection system and a nationwide system of logistics \& warehousing, allowing us to see the beautiful model of "cradle to cradle" coming into being here. However, there is still a long way to go to apply this model in countries and regions with relatively backward technical means and economic conditions [10].

\section{The Deficiency of Education Resources of Production and Life-Oriented Sustainable Fashion Design}

For the common interests of mankind, the education of sustainable development has long been attached great importance by countries from all over the world, and UNESCO put forward the "10-Year Education Plan for Sustainable Development" as early as 2005 . In November 11, 2018, the Summary Conference of 20 Years' China ESD Achievements was held in Beijing, in which more than 200 scholars from around the world and UNESCO discussed the ESD achievements that China had made overt the past 20 years and the direction of global education of sustainable development in the future. [11] A lot of achievements have been made in the education of sustainable development, yet since the research on sustainable fashion began late, from the micro perspective, there are deficient education resources in the field of the education of sustainable fashion design, and only a few higher education institutions in China, such as Donghua University, Beijing Institute of Fashion Technology and Wuhan Textile University have conducted research on sustainable fashion design on a certain scale. When the author searched the keywords of "sustainable fashion design" and "education" on CNKI, only 8 papers could be found, and after reading them carefully, it's found that only 5 were closely related to the education of sustainable fashion design. Since overseas education of sustainable fashion design began earlier, there are more abundant resources, and the research achievements made by scholars represented by Professor Frances Corners and Professor Kate Flatcher at UAL, Centre for sustainable fashion have attracted the attention and discussion of the international community of fashion design. However, since the education of sustainable fashion design involves many fields, such as art, engineering, philosophy and sociology, and the educational practice is mainly concentrated among graduate students, large-scale education of sustainable fashion design is still difficult to carry out [12].

Besides the deficient education resources of the education of sustainable fashion design for designers, resources of sustainable fashion education related to the life of consumers are literally a desert. The foundation for consumers to accept sustainable fashion can only be built by properly inculcating the concept of sustainable fashion, initiating aesthetic discussion on sustainable fashion, providing suggestions on a sustainable lifestyle and teaching skills of clothing remaking, etc. fashion design is never a one-way activity of outputting, and sustainable fashion must be realized through the continuous positive interaction between designers and consumers. [13]

\section{The Powerless Practice of Sustainable Fashion Design Under the Restriction of Realistic Conditions}

The report of the $18^{\text {th }}$ National Congress of the Communist Party of China particularly emphasized the "five-sphere" integrated plan, in which the ecological civilization construction was integrated into the whole process and all aspects of economic, political, social and cultural development. Since the $19^{\text {th }}$ National Congress of the Party, a series of policies and regulations aiming to protect the interests of the environment, the laborers and the enterprises have been gradually studied, introduced and improved. However, in the process of practice, since some laws and regulations are rather scattered and general, they are with low operability [14], leading to the result of failing to achieve expected results in many aspects of the work. Many enterprises have also paid particular attention to the issue of sustainability of clothing, but the current survival conditions of small and medium-sized clothing enterprises in China are harsh, and "going to the bottom and the lowest point" has become a principle of survival in the industry. [15] Due to the high cost of sustainable fashion design and the firm barriers of clothing engineering, many small and medium-sized enterprises can not practice sustainable fashion design for the sake of survival. There are even unscrupulous enterprises misleading consumers with the crooked propaganda of "green washing", which has had a very negative impact on the market of sustainable clothing. According to various sources of research data, although consumers' desire to buy green 
products has been gradually rising in recent years, the mainstream consumer groups int he market have remained unchanged. As a result of the actual demand of the market, designers' practice of sustainable design can only stay in the planning stage in most cases but can not be realized in the market. And in such aspects as the recycling and redesign of sustainable clothing, such practical problems as difficulties in recycling, classification, logistics and storage have to be faced Under the restriction of various realistic conditions, designers often feel powerless in the practice of sustainable correction of design.

\section{Conclusion}

As the precondition and main means of the green and sustainable development of the whole fashion industry related to the ecological civilization construction of the whole society, the sustainable correction of design has been widely concerned and actively participated and cooperated by the whole society. Although the environment of sustainable fashion is getting better and great progress has been made in sustainable fashion design, the road ahead is still beset with difficulties, requiring the concerted effort of the whole society.

\section{Funded Project}

This is a general college-level research project of Dongfang College, Zhejiang University of Finance \& Economics. Project No.: 2019dfy020.

This paper is one of the achievements made in the project of On the Optimization of the Slow Fashion Design of "Hangzhou-style" Clothing under the Requirement of Green Development, a general college-level research project of Dongfang College, Zhejiang University of Finance \& Economics.

\section{References}

[1] Gu Qingliang. China Textile under Ecological Civilization [J]. Textile and Garment Weekly. 2013 (5).

[2] Lynda Grose, Kate Fletcher. Fashion and Sustainability: Design for Change [M]. Laurence King Publishing, 2012.

[3] Francis - Kena. Why fashion is very important [J]. "Art Design". 2017 (02).
[4] Jane Milburn. Slow Clothing: Finding meaning in what we wear [M]. Textile Beat, 2017.

[5] Ellen Koehrer, Magdalena Schaffrin. Fashion Made Fair: Modern-Innovative- Sustainable [M]. Prestel, 2016.

[6] Annie Gullingsrud. Fashion Fibers: Designing for Sustainability [M]. Fairchild Books, 2017.

[7] Sass Brown. Re Fashioned: Cutting-Edge Clothing from Upcycled Materials [M]. Laurence King Publishing, 2013.

[8] Smith, Paul, Baille, Jen, McHattie, Lynn-Sayers. Sustainable Design Futures: An open design vision for the circular economy in fashion and textiles [J]. Design Journal, 2017.

[9] Li Minmin. Review of overseas research from green design to sustainable design $[\mathrm{J}]$. "Ecological Economy (Academic Edition)". 2014 (02).

[10] Liu Guangfu. German textile recycling model and its enlightenment to China [J]. Management Observation. 2016 (01).

[11] Li Yuan. Red Culture Inheritance and Green Ecological Development [J]. Journal of Yanan University, 2018.

[12] Kate Fletcher, Dilys Williams. Fashion Education In Sustainability In Practice [J]. «Research Journal of Textile and Apparel». 2013 (02)

[13] Alison Gwilt, Timo Rissanen. Shaping Sustainable Fashion: Changing the Way We Make and Use Clothes [M]. Routledge, 2011.

[14] Shao Juan. Research on legal issues of rural drinking water pollution prevention and control in China [J]. "Guangdong University of Finance and Economics". 2015 (3).

[15] Xin Qingzhi. Ten basic categories of ecological civilization and its construction theory $[\mathrm{J}]$. "Research on Socialism with Chinese Characteristics", 2019.

\section{Biography}

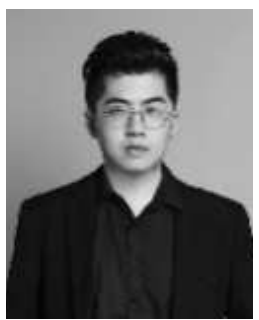

Yizhou Zhang (1989-), Male, native of Huaibei, Anhui Province, lecturer in fashion design, Zhejiang University of Finance and Economics, Research Area: Sustainable Fashion Design. 